\title{
Water Flow Path Characterization in Shallow Vadose Zone Using Tensiometers
}

\section{-A Technical Report and the Preliminary Results of a Pilot Project}

\author{
Mohammad Hassan Rezaie-Boroon, Omar Acosta, Rodrigo Chipres, Cheryl Cox, Frank Diemel, \\ Norman Ho, Shaonan Li, Ricardo Lopez, Matthew Luque, Mayra Martinez, Dennis Palacios, \\ James Wright
}

Geosciences and Environment Department, California State University, Los s Angeles, USA

Email: mrezaie@calstatela.edu

How to cite this paper: Rezaie-Boroon, M.H., Acosta, O., Chipres, R., Cox, C., Diemel, F., Ho, N., Li, S.N., Lopez, R., Luque, M., Martinez, M., Palacios, D. and Wright, J. (2017) Water Flow Path Characterization in Shallow Vadose Zone Using Tensiometers-A Technical Report and the Preliminary Results of a Pilot Project. Journal of Water Resource and Protection, 9, 10821096.

https://doi.org/10.4236/jwarp.2017.99071

Received: June 30, 2017

Accepted: July 30, 2017

Published: August 2, 2017

Copyright () 2017 by authors and Scientific Research Publishing Inc. This work is licensed under the Creative Commons Attribution International License (CC BY 4.0).

http://creativecommons.org/licenses/by/4.0/

\begin{abstract}
In this project, we will present the findings of a study using Tensiometer systems designed to investigate the water flow path pattern in shallow vadose zone. The purpose of this paper is to evaluate water flow path in shallow vadose zone and to calculate the infiltration rate and hydraulic conductivity of a soil using Tensiometer. We have measured the subsurface water flow paths in sandy clay loam soil following infiltration experiment using Tensiometers. The matric potential and hydraulic conductivity measurements show that subsequent infiltration and water movement in unsaturated (vadose) zone are vertical, but it can have large lateral component under steady condition. This shows that water moves generally from high water content to lower water content region. Average pressure head for the percolation test conduction locations $\mathrm{EB}$ and $\mathrm{HB}$ was -30 and $-80 \mathrm{~cm}$ respectively. Hysteresis produces another interesting situation when the soil is drained. We found that the wetter portion of the soil in vadose zone could be at a lower potential (head) than the dryer portions, resulting in lateral driving force for a preferential flow of water from the dryer to the wet soil. The infiltration rate for the $5 \mathrm{~cm}$ ponded water was calculated at $5.45 \mathrm{~cm} / \mathrm{hr}$. The infiltration rate curve shows that the rate of infiltration decreases with the time. When infiltration first starts, the wetting front is steep and very close to the surface. Similarly, due to the pressure head gradient, large value for infiltration is recorded. Under these conditions, we believe that the gradient in pressure head is responsible for the rapid movement of water into the dry soil. The effect of gravity is less on water during the initial stages of infiltration; however, it is more effective for preferential flow pattern. In the latter infiltration event, the wetting front has moved deeper into the soil. As a result, the pressure head gradient at the surface is much smaller and consequently has little effect. When the pressure
\end{abstract}


head is equal zero, infiltration rate approaches almost to the lowest level. We also observed that even a minor change in soil-water pressure due to slope could change both direction and magnitude of water flux.

\section{Keywords}

Tensiometer, Water Pollution, Contamination Migration, Infiltration, Vadose Zone

\section{Introduction}

California's quality of life and economy is inextricably linked to water. Whether viewed as a resource or commodity, water is the basis for our agriculture, municipal, industrial, environmental, and aesthetic well-being. It has been making a conscious effort to quantify the solute transport in the vadose zone and to manage and regulate land use effectively as it applies to watershed management. In addition, specific problems of water and solute balancing in watersheds are caused by the almost unknown interactions between surface water seepage and groundwater in the unsaturated zone. The soil has the capacity to store water in its pores and provide part of it to the plants to the extent of their needs. By the monitoring of matric water potential in the ground, it is possible to determine the amount of water needed to be replaced to the plants by irrigation. The appropriate irrigation can significantly reduce the amount of water applied, minimize loss of water and soil, increase crop yield, and reduce production costs [1]. In this regard, some Tensiometers are used in irrigation scheduling to help farmers and other irrigation managers to determine when to water [2] [3] [4]. In conjunction with a water retention curve, Tensiometers are useful tools to determine how much to water. Furthermore, Tensiometers can also be used in the methodical study of plants and soils. Likewise, as in [5], the authors have used Tensiometer for monitoring soil pressure head and water content during three wetting and evaporation cycles. They compared water retention curves and hydraulic conductivity for packed columns with and without additions of surface compost. As in [6] the authors installed Tensiometers in the unsaturated zone, at different depths to determine flow patterns, while suction Tensiometers were also used for water sample chemical determinations. Their findings show that in the sandy loam plot (Hacienda Real), the unsaturated zone is characterized by low water retention, showing a high transport capacity, while the other two plots of silty composition presented temporal saturation due to La Niña events (20102011) [6]. Traditionally, a Tensiometer is installed in the soil to measure the amount of actual evapotranspiration, which is released by plants. However, in soil science, it is used as a measuring instrument to determine the matric water potential (soil moisture tension) in the vadose zone. Tensiometers are perhaps the most common method of measuring matric potential in the field and are described in detail by [7]. Yet, it allows us to identify where environmental conta- 
mination has come from and where it has spread. Different Lysimeter types may incorporate various combinations. Zero-tension and suction Tensiometer are used to collect water and contaminants that are mobile in the soil [8]. In addition, it has been used for solute balancing in soil water [9] and monitoring the spread of contamination throughout soil and water. Ng et al. (2016) [10] have used Tensiometer to monitor the variations of pore-water pressure and water content with depth for a percolating water in three-layer landfill. Duthe et al. (2005) [11] has installed shallow and deep Tensiometer nest for monitoring of subsurface liquid flux and water content using subsurface material hydraulic/physical properties such as porosity, density, water retention, and Hydraulic conductivity characteristic.

We know that the links between geology, soil, and the groundwater quality have become evident [12] as the near-surface region of Earth has been referred as critical zone [13]. While the water retention behavior of soils is an essential aspect of understanding the unsaturated behavior of soil materials [14], the landscape morphology also affects potential gradients for water flow above and below the Earth's surface. For planning and design of subsurface drainage in the agricultural field, understanding of water flow pattern in the subsurface is necessary [15]. Equally, the direction and magnitude of the vertical head gradient in vadose zone is a crucial parameter for calculating the direction and rate of the soil water movement [16]; according to Darcy's law, the water flux is proportional to head gradient. In addition, water movement in the soil determined by the distribution of potential within the soil profile. Water tends to move from areas of lower metric potential to higher metric potential. This project validates the hydraulic head concept for the vadose zone by measuring the direction and magnitude of the vertical head gradient in the vadose zone by installing Tensiometers. Similarly, we also calculate the hydraulic conductivity of soil in shallow vadose zone. To accomplish this objective, we installed four Tensiometers to measure this quantity in the field as a pilot project. Not only the use of Tensiometer helps us understanding the subsurface preferential flow [17] and overall the water flow pattern in the subsurface, but also the Tensiometers are significant in our understanding of the mechanisms involved in the groundwater contamination. As preferential flow provides a mechanism to bypass most of the porous media, the effects include enhanced solute transport, less filtering and adsorbing of contaminants in the soil, and fast travel to groundwater or tile lines [17].

This pilot project is an exploratory project, which will help us to understand how do watersheds function as a hydro-biogeochemical system and how these systems respond to contaminant loading caused by urban water runoff. This project will present the findings of a study using Tensiometer systems designed to investigate the water balance and the migration of organic and inorganic components in the vadose zone. In the past few decades, great effort has been focused toward clearing the complexities of various interactive physical, chemical, and microbiological mechanisms affecting unsaturated flow and transport, 
with contributions being made by soil scientists, geochemists, hydrologists, soil microbiologists, and others. Unfortunately, a lack of experimental and theoretical understanding of the vadose zone, in turn, has precluded the accurate prediction and management of flow and contaminant transport through it [18] [19].

Measuring the hydraulic head in the vadose zone is quite like saturated zone. We use the similar concept instead the sand pack in piezometer, we have a porous ceramic cup at the Tensiometer's end, the pores are very small, they can't be seen with the naked eye. When the ceramic becomes wet, it is very hydrophilic, pores filled with water, and the water can flow through these pores. It is difficult to force air into these pores and push the water out. So, the inner tube is filled with water and the water can flow in and out across the ceramic cup, but air cannot. After filling it up with water, Tensiometer will put in the soil, the soil in the suction pulls some of the water out, that create suction, which then measured by the gauge. In other word, it measures soil tension.

For vertically installed Tensiometers, the pressure in the head space differs from the pressure at the bottom of the tube due to the weight of the column of water within the Tensiometer [20].

Therefore, in unsaturated soil, the relationship between the gauge reading $\left(\psi_{\text {gauge }}\right)$ in units of pressure $\left[\mathrm{ML}^{-1} \mathrm{~T}^{-2}\right.$ whereas, $(L)$ length, $(M)$ mass, and $(T)$ time], soil matric potential, and soil air potential is:

$$
\psi_{m}+\psi_{a}=\psi_{\text {gauge }}+\rho_{w} g L
$$

where in Equation (1), $L$ is the length of the column of water, $\psi_{m}$ (or negative $h$ ) is matric potential, $\psi_{a}$ is air potential for unsaturated zone, and $\rho_{w}$ is the density of water. If the Tensiometer is installed horizontally, then there is no effect on the column of water and $L$ will be equal zero. If the Tensiometer is installed at an angle from vertical, then $L$ is the difference in elevation between the cup and the gauge [20].

If the soil is unsaturated, $\psi_{m}$ will be negative, but the gauge reading may be positive, depending on $\psi_{a}$ (which can be positive or negative depending on whether the soil air pressure is greater than or less than atmospheric).

Since there is no way to differentiate between $\psi_{m}$ and $\psi_{a}$ using a Tensiometer, the air pressure component is often ignored and it is assumed that:

$$
\psi_{m}=\psi_{\text {gauge }}+\rho_{w} g L
$$

To get matric potential head or pressure head, Equation (2) is divided by $\rho_{w} g$ [20]

$$
h=\frac{\psi_{\text {gauge }}}{\rho_{w} g}+L
$$

The overall goal of this paper is to use Tensiometer to evaluate and to assess a) water flow path in shallow vadose zone b) to calculate the infiltration rate and hydraulic conductivity of a soil. The further goal of this paper is to carry out a Tensiometer experiment for quantifying the water preferential flow in soil and to 
recognize the physical, chemical and biological features that rule water and contaminant movemenz research goal is to develop an experimental and numerical model that follows the migration of contaminants, including organic and inorganic compounds through surface water and in the vadose zone. By conducting this pilot project, we developed a method for quantitative measurements of exchange and flux rates in example, water and solute transport from the surface water and groundwater interaction in this critical zone at the local and regional watershed scales. We performed this experiment in both lab and field scale. This is the first step in understanding and modeling of flow homogeneity as well as heterogeneity in as field scale. The findings of the project will increase the effectiveness of the future projects on characterization and modeling of the physical, chemical and biologic of subsurface and terrestrial environments and to allow for more informed scientific and management decisions.

\section{Materials and Methods}

\subsection{Study Site}

As a part of the vadose zone hydrogeology project, students performed Tensiometer experiment, collecting data from different Tensiometers in Rancho Castillo, CA in 2016 ( $34^{\circ} 03^{\prime} 56.80^{\prime \prime N}, 118^{\circ} 10^{\prime} 19.46^{\prime \prime} \mathrm{W}, 478$ feet m.a.s.l) (Figure 1(e)). The infiltration rate and hydraulic conductivity of soil were assessed and modeled. The prevailing soil type is sandy clay loam. The slope of the investigated study site is $5.58^{\circ}$.

\subsection{Experiment Set up Process and Procedures}

We conducted infiltration experiments and measured variations in the headgradient as a function of time. The tools were used to carry out the experiment include four Tensiometers (Irrometer, model R), a hand shovel, two hand augers (AMS), buckets, measurement tools (tape measure and level for the construction of infiltration pit), tap water, deionized water, plastic rubber hammer, and gloves. In addition, the data were recorded on excel worksheet and the Hydrus $-1 \mathrm{D}$ was used to model the flow. Four Tensiometers were installed using a hand gouge auger. The gouge soil auger is pushed into the soil, twisted and recovered to create a $60 \mathrm{~cm}$ hole for each Tensiometer. Two of the Tensiometers were installed uphill and another two downhill. The two on top were labeled "Hydro.Top", hereafter "HT" and "Eng. Top hereafter ET" and the two bottom ones were "Hydro Bottom" here after "HB" and "Eng. Bottom" hereafter "EB" respectively. The "HT" and "HB" labeled Tensiometers were in line with each other, whereas the "ET" and "EB" Tensiometers were in line with one another (Figures $1(\mathrm{c})-(\mathrm{f})$ ).

A Tensiometer consists of an airtight, water-filled, plastic tube with a porous ceramic or steel cup at the bottom (Figure 1(a) and Figure 1(b)). It provides the 


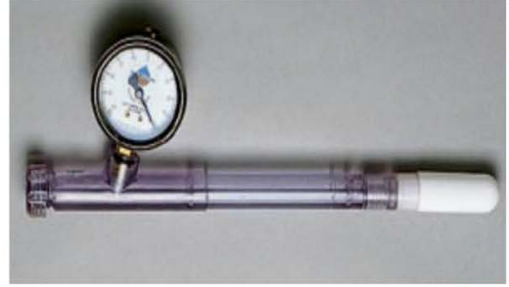

(a)

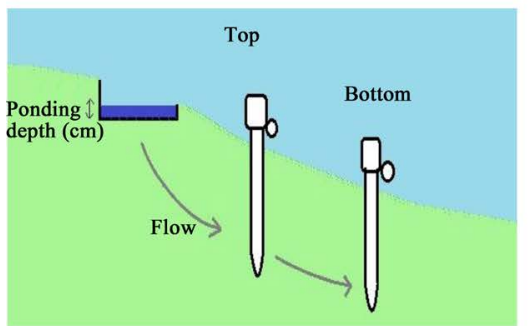

(c)

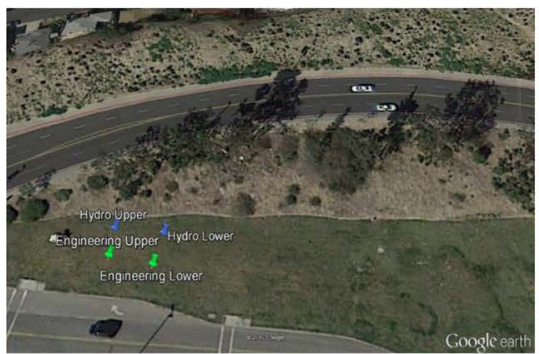

(e)

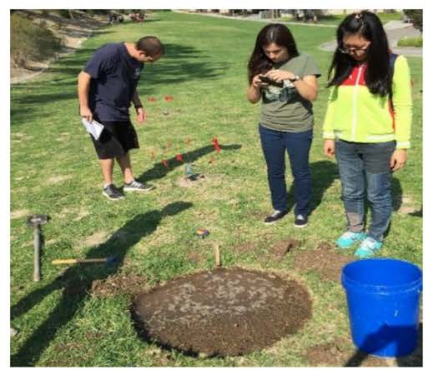

(g)

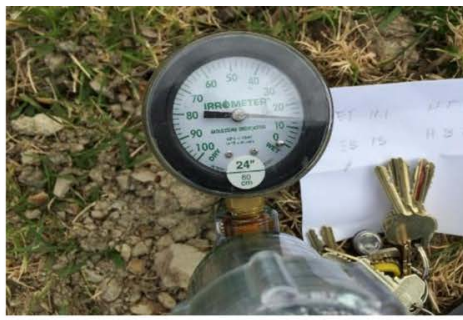

(b)

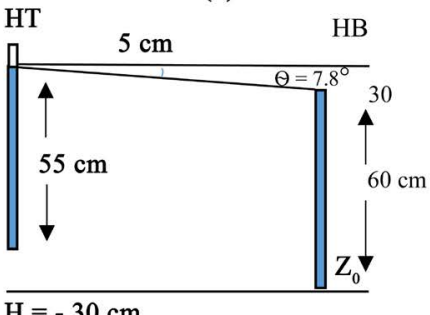

(d)

Eng. Tensiometer

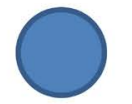

ET

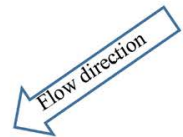

(f)

Hydro. Tensiometer

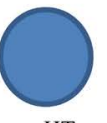

HT
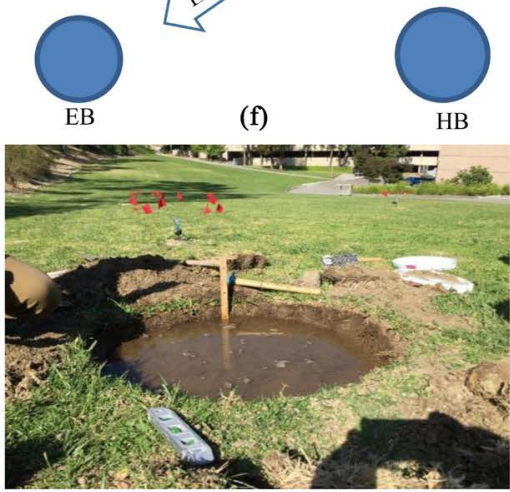

(h)

Figure 1. (a) Tensiometer with a porous cup at the bottom and a vacuum gauge at the top. (b) Vacuum gauge for pressure measurement. (c) The side view drawing of Tensiometer setup. (d) The distance between Tensiometers and the slope degree. (e) The Hydro Group Tensiometers are indicated by blue button and the Engineering Group Tensiometer is indicated by green button on Google Earth map. (f) Top view representing the dominant water flow path (g) and (h) Installing the Tensiometer HT and HB and infiltration pond.

user with accurate information on soil moisture status regardless of soil type. The instrument measures in centibars $(\mathrm{cb})$ or kilopascals $(\mathrm{kPa})$ of soil water tension. This value represents the energy a plant's root system uses to draw water from the soil. Understanding soil moisture activity helps the user make informed irrigation scheduling decisions resulting in improved yield and quality while reducing water, fertilizer, labor and energy costs. For example, a gauge reading of $50 \mathrm{cb}(\mathrm{kPa})$ indicates that the roots are extracting the same amount of moisture whether the crop is planted in sandy soil or clay soil. The pores in the cup are 
small enough to retain the water under pressures (positive or negative) of usually $50-200 \mathrm{kPa}$. The water moves in or out of the tube in response to the soil matric potential of unsaturated soils. A static equilibrium is reached (water stops moving in or out of the tube) when the potential energy of the water inside the Tensiometer at the depth of the cup is the same as the potential energy of the soil water just outside the cup. This increase reduces the air pressure in the head space at the top of the tube, which is measured with a vacuum gauge, manometer (water or mercury), or pressure transducer [20]. Suction Tensiometers collect pore water from unsaturated soil. After installation below ground level, vacuum is applied to the Tensiometer through tubing leading from the Tensiometer to the ground surface. The negative air pressure created inside the Tensiometer draws pore water into the Tensiometer through the porous, stainless steel section of the Tensiometer [20]. According to Irrometer's operation handout [21], due to the Tensiometer's unique principle of operation, no calibrations was necessary under normal operating conditions for different soil types.

The experiment site location initially illustrated an even plane, however, after measuring the elevation change, it became evident that there was a general slope tilting from upper HT towards EB diagonally with the slope of 5.58 (Figures 1(c)-(f)). A one-meter diameter hole (radius of $50 \mathrm{~cm}$ ) was dug and filled with approximately 10 gallons of water with a starting water depth of $10 \mathrm{~cm}$ (Figure 1 (g) \& Figure 1(h)). The water level was measured every 5 minutes until the 10 gallons of water fully infiltrated the soil. The Tensiometer readings were also taken as well. The pressure head in the soil was measured using the following Equation (4):

$$
H=Z+L+P_{G}
$$

where

$P_{G}$ is pressure head at the cup,

$Z$ is elevation head,

$L$ is distance.

From difference in elevation you can calculate the head gradient, and that will be what driving the flow vertically.

$$
\text { Hydraulic Gradient }=\frac{d_{H}}{d_{l}}
$$

$d_{H}=\left(\right.$ head $_{2}$ - head $)$,

$d_{1}=$ different in distance.

Based on the above calculation the head gradient was 0.167 . The Wooding Equation was used for measuring the hydraulic conductivity using "Sandy Clay Loam" as soil type.

$$
I_{s}=K\left(1+\frac{4 \lambda_{c}}{\pi r}\right)
$$

Then solved for $K$ and the equation is as follows

$$
K=\frac{I_{s}}{1+\frac{4 \lambda_{c}}{\pi r}}
$$


To calculate the time for infiltration rate, the Green-Ampt infiltration equation was used under incipient ponding conditions at the surface. We assumed that the initial water content in the soil is $0.13 \mathrm{~cm}^{3} \mathrm{~cm}^{-3}$.

$$
\begin{gathered}
I(t)=K\left(h_{0}\right) t+\Delta h \Delta \theta \ln \left(1+\frac{I(t)}{\Delta h \Delta \theta}\right) \\
\Delta \theta=\theta_{0}-\theta_{i} \\
\Delta h=h_{0}-h_{f}
\end{gathered}
$$

The first formula when solve for time becomes

$$
t=\frac{I(t)-\Delta h \Delta \theta \ln \left(\frac{I(t)}{\Delta h \Delta \theta}\right)}{K\left(h_{0}\right)}
$$

\section{Results and Discussion}

Overall, the bottom Tensiometers (HB and EB; Figures 1(c)-(f)) experienced higher soil pressure head caused by water flow downward toward the bottom Tensiometers. This has caused an increase in moisture content of soil at the Tensiometer's ceramic cup. This was evident after each infiltration test. Due to the gentle slope of the area at the experiment site, the infiltrated water migrated from the top Tensiometers toward the bottom one due to gravity flow (Figures $1(c)-(f))$. After the infiltration test, a slight rise in the top Tensiometer readings (ET and HT Tensiometers; Figure 1(d) \& Figure 1(e)) occurred, but as water movement proceeded downward a larger rise was observed in the bottom readings (EB; Figures $1(\mathrm{c})$-(f)). However, there was a greater correlation between the HT and EB (Figure 1(f)). This may be due to the dominated diagonal slope between the two Tensiometers, which caused a diagonal direction of moisture movement from the HT Tensiometer to the EB Tensiometer. This will yield the HT to have a higher matric potential than the EB Tensiometer. Table 1 shows the Tensiometer reading for total 12 days.

According to these data the Tensiometer reading is 0 at the first 5 days and then it became stable, and became more and more negative. There was some abnormally in readings on May 18/16, where suddenly became less negative and even changed to 0 for the top Tensiometer. This may have been caused by human error. But the bottom part shows a perfect and normal trend as we were expecting. Table 1 clearly shows when the water content decreases and soil gets drier, the matric potential becomes larger and the Tensiometer reading becomes more negative. The reading occurred during and after infiltration, however, after infiltration the hydro-group Tensiometer HT had the largest difference between soil pressure head.

The graphs (Figure 2 and Figure 3) plot the matric potential (as measured by the Tensiometer) versus time. The readings for the HT Tensiometer (Hydro Top) are blue and the EB (Engineer Bottom) is orange. As can be seen from the data, the matric potential begins to drop around the 130-min mark for the HT. 
This means that the waterfront has reached that Tensiometer and passed it. The drop also indicates that the soil was becoming wetter at that Tensiometer's ceramic cup. Also at the 130-minute mark, the EB matric potential is increasing slightly. This shows that the ceramic cup is slightly getting drier and has a higher potential to intake water. The EB Tensiometer did not show a drop in matric potential until around 180 minutes. This indicates that the infiltration of the ponded water has reached that Tensiometer. After or around 250 minutes, the matric potential has increased again indicted the water front of the infiltration has passed the EB Tensiometer.

The graph in Figure 4 is a plot of the cumulative standing water difference $(\mathrm{cm})$ versus time (minutes). A linear fit was used to get the average infiltration

Table 1. Tensiometer readings for HT and ET Tensiometers.

\begin{tabular}{|c|c|c|c|c|c|}
\hline \multirow[t]{2}{*}{ Date } & \multirow[t]{2}{*}{ Time } & \multicolumn{2}{|c|}{ Hydrology Group } & \multicolumn{2}{|c|}{ Engineers Group } \\
\hline & & $\begin{array}{c}\text { Upper } \\
\text { Tensiometer } \\
(\mathrm{HT})\end{array}$ & $\begin{array}{c}\text { Lower } \\
\text { Tensioner } \\
\text { (HB) }\end{array}$ & $\begin{array}{c}\text { Upper } \\
\text { Tensiometer } \\
\text { (ET) }\end{array}$ & $\begin{array}{c}\text { Lower } \\
\text { Tensiometer } \\
\text { (EB) }\end{array}$ \\
\hline $5 / 13 / 2016$ & 13:04 & 0 & 0 & -- & -- \\
\hline $5 / 14 / 2016$ & $06: 52$ & 0 & 0 & 0 & 0 \\
\hline $5 / 14 / 2016$ & $15: 06$ & 0 & 0 & 0 & 5 \\
\hline $5 / 15 / 2016$ & 13:04 & 0 & 1 & 0 & 5 \\
\hline $5 / 16 / 2016$ & 11:05 & 0 & 2 & 0 & 5 \\
\hline $5 / 16 / 2016$ & $17: 26$ & 0 & 2 & 2 & 5 \\
\hline $5 / 17 / 2016$ & 09:15 & 0 & 2.1 & 2.1 & 5 \\
\hline $5 / 18 / 2016$ & 09:02 & 2.5 & 5 & 5 & 6 \\
\hline $5 / 18 / 2016$ & $16: 12$ & 2.5 & 5 & 5 & 7.5 \\
\hline $5 / 18 / 2016$ & $16: 52$ & 2 & 6 & 5 & 7.5 \\
\hline $5 / 18 / 2016$ & $19: 52$ & 1 & 5 & 6 & 5 \\
\hline $5 / 18 / 2016$ & $22: 20$ & 0 & 7.5 & 7 & 5 \\
\hline $5 / 19 / 2016$ & 09:15 & 1 & 7.5 & 7.5 & 7.5 \\
\hline $5 / 19 / 2016$ & $12: 19$ & 2.5 & 7.5 & 7.5 & 7.5 \\
\hline $5 / 19 / 2016$ & $13: 30$ & 5 & 7.5 & 8 & 8 \\
\hline $5 / 19 / 2016$ & 18:00 & 5 & 7.5 & 7.5 & 8 \\
\hline $5 / 20 / 2016$ & 08:06 & 4.5 & 9.5 & 7.5 & 9 \\
\hline $5 / 20 / 2016$ & $17: 14$ & 10 & 9 & 9.5 & 11 \\
\hline $5 / 21 / 2016$ & $12: 00$ & 10 & 13 & 12 & 10.5 \\
\hline $5 / 21 / 2016$ & 00:00 & 12 & 16 & 14 & 13 \\
\hline $5 / 23 / 2016$ & $21: 19$ & 14 & 21 & 16.5 & 13 \\
\hline $5 / 24 / 2016$ & 09:15 & 15 & 22 & 18.1 & 13 \\
\hline $5 / 24 / 2016$ & $14: 00$ & 16 & 22 & 19 & 15 \\
\hline $5 / 24 / 2016$ & $20: 09$ & 16 & 23.5 & 18 & 14 \\
\hline
\end{tabular}




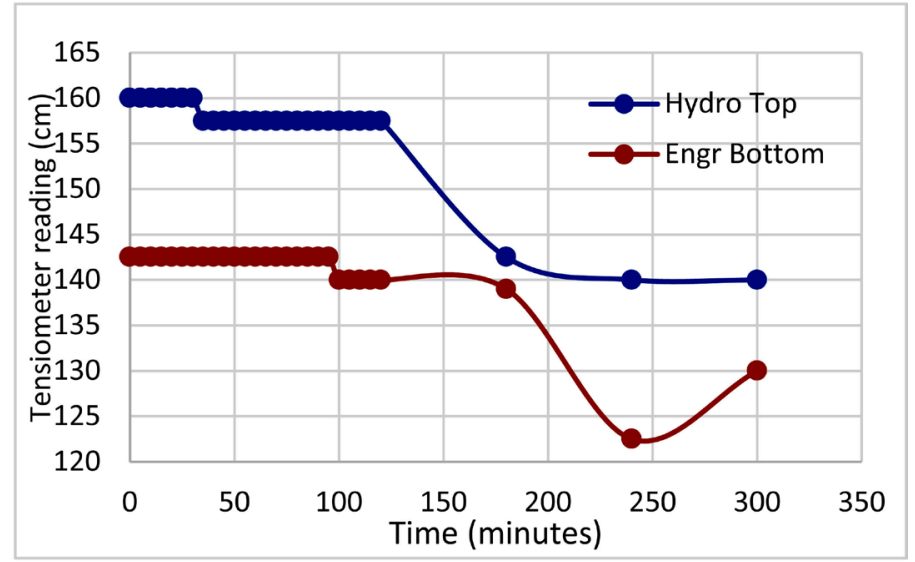

Figure 2. The Hydro and Engineering group top (HT) and bottom (EB) matric potential.

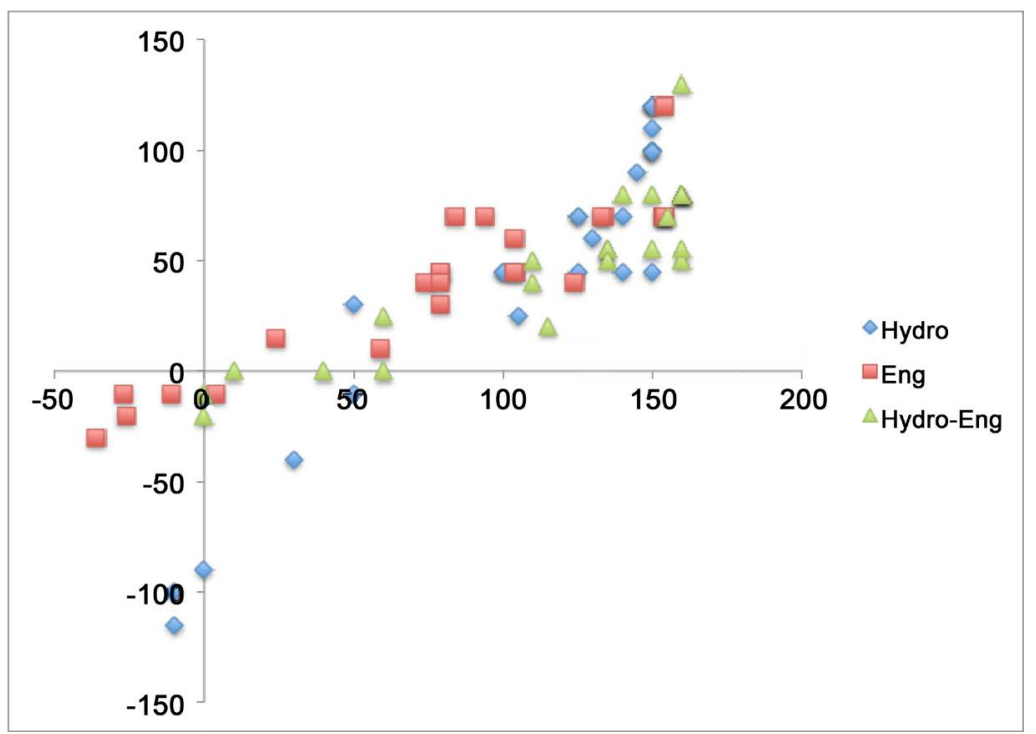

Figure 3. The relationship between all ET and HB Tensiometer values.

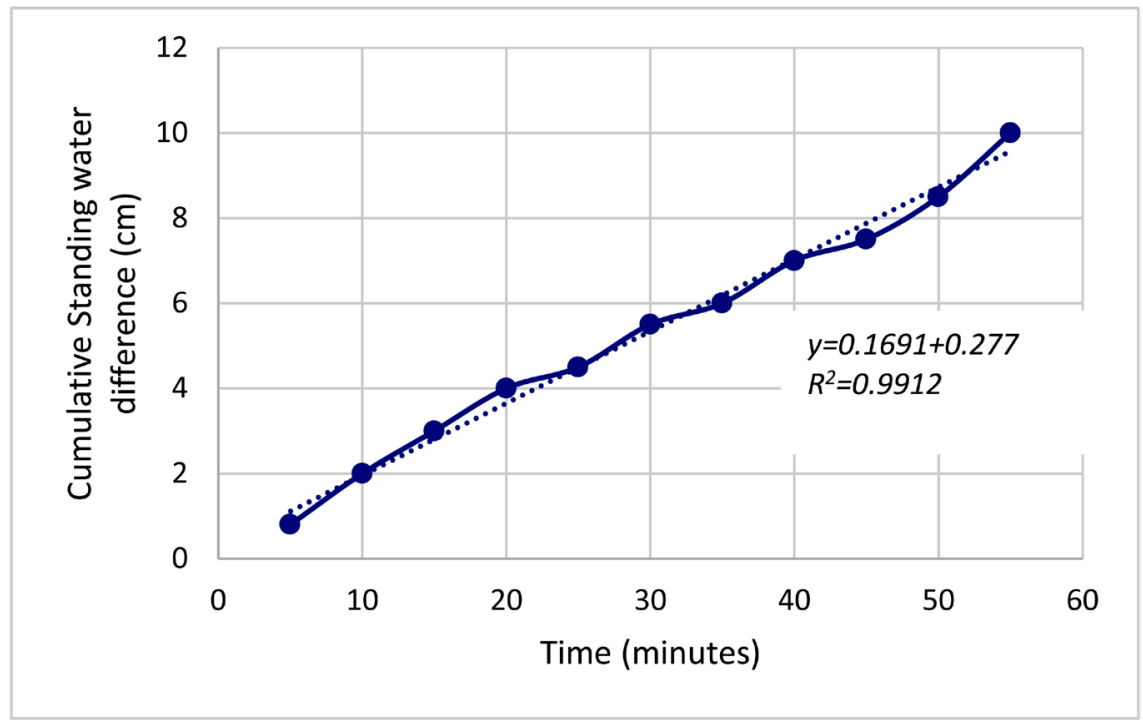

Figure 4. The infiltration test vs. time (min). 
rate of the ponded water into the soil, which indicates that the infiltration rate is approximately $0.1691 \mathrm{~cm} / \mathrm{min}$. Just looking at the data alone it is also easy to see that the infiltration was rather constant and very close to linear with a correlation of $99 \%$.

To calculate the Infiltration rate of the soil we need several parameters including $h_{0}, \lambda_{c}, \theta_{i}$ and $\theta_{0}$, and $K_{s} . \theta_{0}$, is the water content at the surface and extends to the wetting front. $h_{0}$ corresponds to the water content $\theta_{0} \cdot h_{f}$ is the pressure head at the wetting front. $K_{s}$ is saturated hydraulic conductivity. These parameters are listed for "sandy clay loam" in referring literature [20]. According to the equation 8 and 9, we calculated the infiltration rate for $5 \mathrm{~cm}$ ponded water. Based on these data the infiltration rate of the $5 \mathrm{~cm}$ pond was calculated $0.0908 \mathrm{~cm} / \mathrm{min}$ or $5.54 \mathrm{~cm} / \mathrm{h}$ (Table 1$)$. Based on the above calculation the hydraulic conductivity for sandy clay loamy soil was $5.45 \mathrm{~cm} / \mathrm{h}$ or 54.5 $\mathrm{mm} / \mathrm{h}$.

From the following figure (Figure 5) the infiltration rate curve, the rate decreases with the time. When infiltration first starts, the wetting front is steep and very close to the surface. Because the pressure head gradient is large, producing large value for infiltration. Under these conditions, the gradient in pressure head is responsible for the rapid movement of water into moist soil. We believe that the effect of gravity has less effect on the water during the initial stages of infiltration. Later in the infiltration event, the wetting front has moved deeper into the soil. As a result, pressure head gradient at the surface is much smaller and has less effect. When it approaches zero, infiltration rate almost equals to $K_{s}$. Under these circumstances, a minimum infiltration rate is reached and it is approximately the $K_{s}$. Hysteresis produces another interesting situation here when the soil is drained. We found that the wetter portion of the soil of vadose zone could be at a lower potential (head) than the dryer portions, resulting in lateral driving force for a preferential flow of water from the dryer to the wetter soil.

Figure 5 shows that the infiltration rate will decrease over time. This indicated that as more of the water infiltrates the rate of the water infiltrating de-

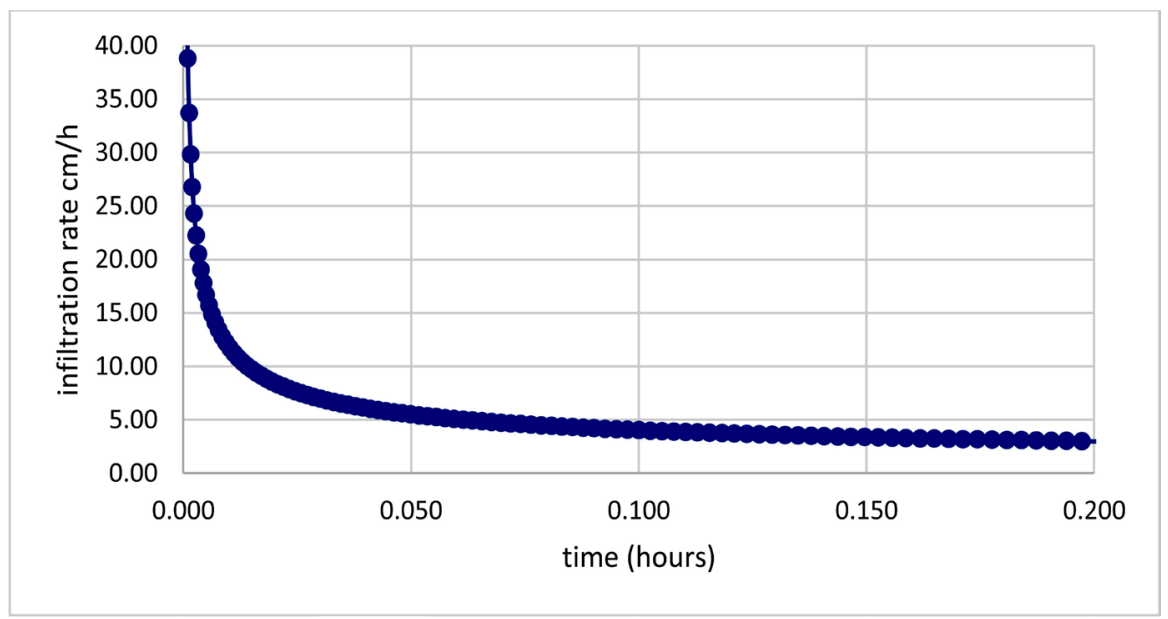

Figure 5. Infiltration rate vs. time $(\mathrm{cm} / \mathrm{h})$. 
creases. This is due to the less water infiltrating as which is decreasing the head pressure.

$\mathrm{Ng}$ (2016) [10] has used similar concept for a heterogeneous soil column (in a landfill) with clay layer at the bottom. Numerical parametric simulations reveal that with an increase of saturated clay permeability by three orders of magnitude the amount of percolation is approximately $0.1 \mathrm{~mm}$ after $12 \mathrm{~h}$ of constant water ponding, which is equivalent to or greater to a 1000 years flood.

Water and transport processes are known to be strongly affected by both soil structure and soil texture [22]. The water entering soil, whether as rain or irrigation is never pure. It contains soluble constituent including soluble products of mineral, organic matter decomposition as well as fertilizers and pesticides. Besides, the soil solution carries its solute load. At the same time, solutes react among themselves and interact with the solid matrix of the soil through chemi$\mathrm{cal}$ and physical processes. These interactions involve and influenced by $\mathrm{pH}$, temperature, concentration, and composition of soil solution [23]. In case of contaminant transport through the soil from runoff and/or irrigation, the "first flush" or initial runoff concentration [24] is very critical. By observing our experimental approach, we believe that the first load of solute transport through soil solution is not consistent with the uniform flow pattern predicated with the Richards equation [25]. Additionally, the water and solute may move preferentially through the macrospores, fractures, or other structural voids and/or biological channels [20]. We believe this is not only due to the presence of those structural voids but it is also due to the slope of soil layer. The gradient may cause the preferential flow taking place faster along certain pathways. Other studies by [26] [27] has documented a similar correlation between gradient and preferential flow. They consider the funneling of flow due to the presence of sloping soil layers that redirect the downward water flow. This was precisely what we could produce from ponded water experiments in this study. In contrast, the authors in [28] have observed the fingering when there was no slope to the coarse texture layer in their lab experiment. Walter et al. (2000) [29] also investigated the effect of slope and infiltration rate. We observed the same phenomena in our infiltration test experiment. Percolated water flowed diagonally from HT to EB and not from HT to HB (Figure 1(f)) when the wetting front reached the layer (probably coarser layer), which could not enter because the wetting pressure head was less than the water entry value. Since there was a slope to the layer, water funneled laterally reaching the HB Tensiometer diagonally. Additionally, the authors in [30] used a combination of high-resolution data with time lapse geophysical images, which provided a better characterization of infiltration mechanisms and preferential flow path. They obtained similar results with different method. Their tracer infiltration test was completed over a heterogeneous vadose zone composed of backfilled materials, sands and silts, and unsaturated fractured chalk. Monitoring results during a five-day period revealed the formation of a tracer plume in the upper backfilled deposits, while some of the tracer migrated laterally following preferential pathways. Slow vertical flow through matrix pores 
was found to be dominant under dry conditions. We found hysteresis as another interesting situation here when the soil, which was drained following our infiltration experiment. We found that the wetter portion of the soil of vadose zone could be at a lower potential (head) than the dryer portions, resulting in lateral driving force for a preferential flow of water from the dryer to the wetter soil. According to [31], while this is true at high water contents, where pores are filled by water or a film of water covers the particles, it is less likely for drier states, where the adhesion of water menisci to the surface of the particles is controlled by the nature of the particle surface (chemistry and surface roughness) and the presence of organic matter.

The application of this type of flow is for designing the capillary barrier or caps for diverting infiltering water around hazardous waste storage sites. The authors in [32] used HYDRUS-2D to simulate the effect of capillary barrier with a $5 \%$ slope under different rainfall rates. Therefore, even a minor change in soilwater pressure due to slope could change both direction and magnitude of water flux.

\section{Conclusion}

We conclude that soil-water migration is a key process that affects both the water quantity and quality in the environment; therefore, it needs more attention as far as contaminant transfer to subsurface and eventually to the groundwater table. The water movement in the vadose zone occurs primarily under unsaturated, transient conditions. Moreover, the gravity has a slight effect on water movement during the initial stages of infiltration; however, it is more effective for preferential flow pattern. The preferential flow is one of the most thought-provoking parts of predicting soil water movement; nonetheless various methods have been developed to justify the effect of macrospores, fingering, funnel flow, and spatial variability.

\section{Acknowledgements}

The authors thank the Facilities Services (the irrigation and ground unit) at $\mathrm{Cal}$ State LA for their logistic and support.

\section{References}

[1] Bergalso, J.M.G., Cora, J.E. and Fernando, E.J. (2012) Measurement System of Soil, Water Matric Potential, and Evaluation of Soil Moisture under Different Irrigation Depth. Eng. Agríc., Jaboticabal, 32, 467-478. https://doi.org/10.1590/S0100-69162012000300006

[2] Rawls, W.J., Ahuja, L.R., Brakensiek, D.L. and Shirmohammadi, A. (1993) Infiltration and Soil Water Movement. In: Maidment, D.R., Ed., Handbook of Hydrology, McGraw-Hill, New York, NY, USA, 5.1-5.51.

[3] Thalheimer, M. (2013) A Low-Cost Electronic Tensiometer System for Continuous Monitoring of Soil Water Potential. Journal of Agricultural Engineering, 44. https://doi.org/10.4081/jae.2013.211 
[4] Maddah, M., Olfati, J. and Maddah, M. (2014) Perfect Irrigation Scheduling System Based on Soil Electrical Resistivity. International Journal of Vegetable Science, 20, 235-239. https://doi.org/10.1080/19315260.2013.798755

[5] Logsdon, S.D. and Malone, R.W. (2015) Surface Compost Effect on Hydrology: In-Situ and Soil Cores. Compost Science \& Utilization, 23, 30-36. https://doi.org/10.1080/1065657X.2014.949909

[6] Ortegón, G.P., Arboleda, F.M., Candela, L., Tamoh, K. and Valdes-Abellan, J. (2016) Vinasse Application to Sugar Cane Fields. Effect on the Unsaturated Zone and Groundwater at Valle del Cauca (Colombia). Science of the Total Environment, 539, 410-419. https://doi.org/10.1016/j.scitotenv.2015.08.153

[7] Young, M.H. and Sission, J.B. (2002) Methods of Soil Analysis. Part 3.2.2 Tensiometry, 575-673.

[8] Watmouth, S.A., Koseva, I. and Landre, A. (2013) A Comparison of Tension and Zero-Tension Lysimeter and PRS ${ }^{\mathrm{Tm}}$ Probes for Measuring Soil Water Chemistry in Sandy Boreal Soils in the Athabasca Oil Sands Region, Canada.. Water Air Soil Pollution, 224, 1663.

[9] Knappe, S., Haferkorn, U. and Mattusch, J. (2014) Water and Solute Balances in Recultivated Lignite Mining Dump Soils-Field Data and Lysimeter Experiments. Water, Air, \& Soil Pollution, 157, 85-105. https://doi.org/10.1023/B:WATE.0000038876.59795.c2

[10] Ng, C.W., et al. (2016) Water Infiltration into a New Three-Layer Landfill Cover System. Journal of Environmental Engineering, 142, 4016007-1-4016007-12. https://doi.org/10.1061/(ASCE)EE.1943-7870.0001074

[11] Duthe, D., Lorentz, S., Cameron-Clarke, S. and Oliver, A.J. (2005) Hydraulic Containment, Natural Attenuation and Phytoremediation as a Combined Remediation Strategy for an Industrial Waste Site in South Africa. Third International Phytotechnologies Conference, EPA, ORD, TIFSD Atlanta, GA, Atlanta, 20-22 April 2005. https://clu-in.org/phytoconf/proceedings/2005/7A_Duthe.pdf

[12] Goss, M.J. and Ehlers, W. (2009) The Role of Lysimeter in the Development of Our Understanding of Soil Water and Nutrient Dynamics in Ecosystems. Soil Use and Management, 25, 213-223. https://doi.org/10.1111/j.1475-2743.2009.00230.x

[13] Brantley, S.L., Goldhaber, M.B. and Ragnarsdottir, K.V. (2007) Crossing Disciplines and Scales to Understand the Critical Zones. Elements, 3, 307-314. https://doi.org/10.2113/gselements.3.5.307

[14] Toll, D.G., Asquith, J.D., Fraser, A., Hassan, A.A., Lui, G., Lourenco, S.D.N., Mendes, J., Nogichi, T., Osinski, P. and Striling, R. (2016) Tensiometer Techniques for Determining Soil Water Retention Curves. Unsaturated Soil Mechanics from Theory to Practice-Proceedings of the 6 th Asia-Pacific Conference on Unsaturated Soils, Guilin, 23-26 October 2015, 15-22.

[15] Ebrahimian, H. and Noory, H. (2015) Modeling Paddy Filed Subsurface Drainage Using Hydrus-2D. Paddy and Water Environment, 13, 477. https://doi.org/10.1007/s10333-014-0465-8

[16] Fetter, C.W. (2007) Applied Hydrogeology. 2nd Edition, Merrill Publishing, Columbus.

[17] DiC Arlo, A.D., Bauters, T.W.J., Darnault, D.J.G., Steenhuis, T.S. and Parlange, J.Y. (1999) Lateral Expansion of Preferential Flow Paths in Sands. Water Resources Research, 35, 427-434. https://doi.org/10.1029/1998WR900061

[18] Nielsen, D.R., Van Genuchten, Th.M. and Biggar, J.W. (1986) Water Flow and So- 
lute Transport Processes in the Unsaturated Zone. Water Resources Research, 22, 89S-108S. https://doi.org/10.1029/WR022i09Sp0089S

[19] Coutinho, A.P., Lassabatere, L., Winiarski, T., da Silva Pereira Cabral, J.J., Antonino, A.C.D. and Angulo-Jaramillo, R. (2015) Vadose Zone Heterogeneity Effect on Unsaturated Water Flow Modeling at Meso-Scale. Journal of Water Resource and Protection, 7, 353-368. https://doi.org/10.4236/jwarp.2015.74028

[20] Radcliffe, D.E. and Simunek, J. (2010) Soil Physics with Hydrus: Modeling and Applications. CRC Press, Boca Raton, Florida.

[21] IRROMETER Company (2016) IRROMETER I $^{\oplus}$ Operation Handout. IRROMETER Company, Riverside.

[22] Coquet, Y., et al. (2005) Water and Solute Transport in a Cultivated Silt Loam Soil: 1. Field Observations. Vadose Zone Journal, 4,573-586. https://doi.org/10.2136/vzj2004.0152

[23] Hillel, D. (2008) Soil in the Environment. Elsevier, Berlin, 305 p.

[24] Schiff, K.C., Tiefenthaler, L., Bay, S.M. and Greenstein, D.J. (2016) Effects of Rainfall Intensity and Duration on the First Flush from Parking Lots. Water Journal, 8, 320.

[25] Hendrickx, J.M.H. and Flury, M. (2001) Uniform and Preferential Flow Mechanism in Vadose Zone. National Academy Press, National Research Council, Washington DC, 149-187.

[26] Kung, K.J.S. (1990) Preferential Flow in Sandy Vadose Zone. 2. Mechanism and Implications. Geoderma, 46, 59-71. https://doi.org/10.1016/0016-7061(90)90007-V

[27] Kung, K.J.S. (1990) Preferential Flow in Sandy Soil. 1. Field Observation. Geoderma, 46, 51-58. https://doi.org/10.1016/0016-7061(90)90006-U

[28] Baker, R.S. and Hillel, D. (1990) Laboratory Test of a Theory of Fingering during Infiltration into Layered Soil. Soil Science Society of America Journal, 54, 20-30. https://doi.org/10.2136/sssaj1990.03615995005400010004x

[29] Walter, M.T., et al. (2000) Funneled Flow Mechanisms in Sloping Layered Soil. Laboratory Investigation. Water Resources Research, 28, 427-431.

[30] de Vera Fernandez, N., et al. (2017) Tracer Experiment in a Brownfield Using Geophysics and a Vadose Zone Monitoring System. Vadose Zone Journal, 16. https://doi.org/10.2136/vzj2016.06.0051

[31] Lourenco, S., et al. (2015) Hysteresis in the Soil Water Retention of a Sand-Clay Mixture with Contact Angles Lower than Ninety Degrees. Vadose Zone Journal, 14, 1-8. https://doi.org/10.2136/vzj2014.07.0088

[32] Mallants, D., Volckaert, G. and Marivoet, J. (1999) Sensitivity of Protective Barrier Performance to the Change in Rainfall Rate. Water Management, 19, 467-475. https://doi.org/10.1016/S0956-053X(99)00236-6 
Submit or recommend next manuscript to SCIRP and we will provide best service for you:

Accepting pre-submission inquiries through Email, Facebook, LinkedIn, Twitter, etc. A wide selection of journals (inclusive of 9 subjects, more than 200 journals)

Providing 24-hour high-quality service

User-friendly online submission system

Fair and swift peer-review system

Efficient typesetting and proofreading procedure

Display of the result of downloads and visits, as well as the number of cited articles Maximum dissemination of your research work

Submit your manuscript at: http://papersubmission.scirp.org/

Or contact jwarp@scirp.org 